\title{
Configurações
}

Revista de sociologia

\section{Territórios contaminados, corpos contaminados: Estado, nuclearidade e cidadania em Portugal e França}

Contaminated territories, contaminated bodies: state, nuclearity and citizenship in Portugal and France

Territoires contaminés, corps contamines : état, nucléarité et citoyenneté au Portugal et en France

José Manuel Mendes e Pedro Araújo

\section{OpenEdition}

\section{Journals}

\section{Edição electrónica}

URL: http://journals.openedition.org/configuracoes/893

DOI: $10.4000 /$ configuracoes.893

ISSN: 2182-7419

\section{Editora}

Centro de Investigação em Ciências Sociais

Edição impressa

Data de publição: 5 Fevereiro 2011

Paginação: 33-56

ISSN: 1646-5075

\section{Refêrencia eletrónica}

José Manuel Mendes e Pedro Araújo, «Territórios contaminados, corpos contaminados: Estado, nuclearidade e cidadania em Portugal e França », Configurações [Online], 8 | 2011, posto online no dia 21 fevereiro 2013, consultado o 20 abril 2019. URL : http://journals.openedition.org/ configuracoes/893 ; DOI : 10.4000/configuracoes.893

Este documento foi criado de forma automática no dia 20 Abril 2019.

(c) CICS 


\section{Territórios contaminados, corpos contaminados: Estado, nuclearidade e cidadania em Portugal e França ${ }^{1}$}

Contaminated territories, contaminated bodies: state, nuclearity and citizenship in Portugal and France

Territoires contaminés, corps contamines : état, nucléarité et citoyenneté au Portugal et en France

José Manuel Mendes and Pedro Araújo

\section{Introdução}

1 As histórias locais e nacionais do urânio são sempre parte integrante da história mais vasta e mais complexa que é a do nuclear globalizado. Neste artigo, abordaremos a história do urânio na Urgeiriça, em Portugal ${ }^{2}$, e no Limousin, em França, e mais precisamente a questão de nuclearidade num momento particular daquelas que configuram as temporalidades do urânio nestes territórios.

2 Antes, porém, convém desde já assinalar aquilo que entendemos por nuclearidade. A exposição ao urânio e aos produtos do seu decaimento não é imediatamente acessível aos sentidos e integra, como salienta P. Perreti-Watel (2007: 76), o grupo dos riscos tecnológicos para a apreensão dos quais a ciência se constitui como um mediador incontornável. Apenas a ciência dispõe das técnicas e instrumentos necessários para lhes conferir existência, para estabelecer a "nuclearidade do urânio". E, porém, será a ciência suficiente? Para G. Hecht (2006, 2009), a nuclearidade da exploração de urânio é uma categoria técnico-política continuamente contestada. Os parâmetros da sua definição dependem da história e da geografia, da ciência e da tecnologia, dos corpos e das políticas, dos Estados e dos mercados. O "nuclear" - insiste - é o resultado técnico-político de processos históricos: 
A política molda-lhe as tecnologias, mas as suas tecnologias também lhe moldam as políticas. A realidade material assume, aí, uma extrema importância, [...] [mas], como demonstram inúmeros estudos na área da ciência e da tecnologia, as realidades materiais emergem de redes complexas em que o social e o técnico se interligam de uma forma inextricável. [...] No domínio da exposição ocupacional, por exemplo, os instrumentos, as relações laborais, as disciplinas científicas, as controvérsias entre especialistas, e o saber leigo combinam-se por forma a criar aquilo a que Michelle Murphy (2006) chama "regimes de perceptibilidade", quer dizer, conjugações de factores sociais e técnicos que tornam visíveis certos riscos e efeitos para a saúde, tornando outros invisíveis. [...] A questão científica (e, ao que parece, também presentista e deslocalizada) da causalidade [...] é portanto também, e sempre, uma questão histórica e geográfica. (Hecht, 2009: 3)

3 A análise que nos propomos desenvolver parte de dois territórios nos quais a exploração de urânio foi irreversivelmente marcante. Distintos no impulso que conferiram ao desenvolvimento nacional da indústria nuclear, estes territórios partilham duas importantes semelhanças que serviram de ponto de partida para o exercício comparativo que nos propusemos empreender. Primeiro, a Urgeiriça e o Limousin foram, sem dúvida, os territórios onde, em Portugal como em França, a exploração de urânio mais se desenvolveu e adquiriu dimensão nacional e internacional. Segundo, ambas as histórias da indústria uranífera nestes territórios culminaram, no final do século XX, num reconhecimento tardio do passivo ambiental gerado pela exploração desse minério. Meio século depois, no caso do Limousin, e quase um século passado, no caso da Urgeiriça, findos a extracção e o tratamento de urânio, o momento histórico ao qual ambos os casos nos reportam, é o do tempo incerto da radioactividade, ou seja, um tempo de "redescoberta" da nuclearidade diferentemente mobilizada por diferentes actores e com consequências distintas em ambos os territórios (Brunet, 2004).

O que procuraremos tornar saliente são as diferentes configurações que, em França e em Portugal, assume a relação entre o Estado, o território e a população, quando mediadas pela "redescoberta" da nuclearidade do urânio. Em França, tomamos como ponto de entrada o processo judicial que opôs a associação Sources et Rivières du Limousin (Fontes e Rios da Região Limousin, de ora em diante SRL) à COGEMA, hoje AREVA NC, grupo industrial que, em 1976, sucedeu ao Commissariat à l'Energie Atomique (Comissariado para a Energia Atómica, CEA) ${ }^{3}$. No caso português, partimos dos inesperados protestos que emergiram na sequência da requalificação ambiental da área mineira da Urgeiriça.

\section{As controvérsias e o papel da ciência}

5 As controvérsias são pontos privilegiados para a avaliação do papel da ciência na configuração das políticas públicas e no fechamento ou não dos debates públicos sobre temas não consensuais. Como refere D. Nelkin (1995), o escrutínio da ciência pode constituir uma etapa na avaliação da relação dos cidadãos e do público em geral com a ciência ou, como sugere B. Latour (2005; 2004), ser uma forma de exploração das oportunidades para a construção de novas ferramentas que facilitem a constituição e a presença de novos públicos e de novas formas de cidadania ${ }^{4}$.

6 Constituindo o estudo das controvérsias uma área específica de investigação nos estudos da ciência e da tecnologia, comportando uma vasta literatura e vários estudos de referência, interessa-nos no nosso caso dialogar com os trabalhos que, como refere Mukerji (2007a: 787), dão menos relevo à análise dos processos sociais que determinam o 
que é a ciência legítima e se centram mais no estudo da importância da ciência na esfera pública ${ }^{5}$.

7 E nesta linha específica de investigação cabe referir as análises de A. Kinchy, D. Kleinman e R. Autry (2008), que acentuam o papel diferenciado das instituições estatais na resistência ao discurso e às práticas da indústria da biotecnologia.

8 Segundo os autores, esta indústria procura diminuir o impacto da participação dos cidadãos e das suas organizações representativas (aquilo a que os autores chamam de regulação social da ciência) pela regulação através do cientismo e de análises estritas de avaliação de risco. Também B. Wynne (2006) procede a uma análise crítica da participação dos cidadãos na configuração das políticas públicas e analisa as causas do falhanço das instituições científicas e estatais em colocar as suas culturas institucionais relacionadas com a ciência e a política numa perspectiva dialógica.

9 Também de especial importância para os estudos de caso que apresentamos neste artigo são as propostas de C. Mukerji $(2009 ; 2007 b)$ sobre o papel do Estado na definição de políticas que, mobilizando a ciência e a técnica, sejam outorgantes de responsabilidade pelos mais fracos e pelo bem comum 6 . 0 nosso recurso à análise comparativa está em sintonia com S. Jasanoff (2005: 15) quando esta afirma que, pelo facto de o conhecimento e as políticas serem sempre alicerçados na cultura, há que manter algum cepticismo quanto à possibilidade de não ser problemática a aprendizagem com as experiências alheias. Para esta autora, a análise comparativa faz-se em torno do conceito de cultura política, de maneira a investigar as ligações existentes entre as tecnologias, o conhecimento e o poder no contexto de culturas de decisão e de acção concretas. Dito de outro modo: "Esta abordagem lança luz sobre o modo como a cultura política se reflecte nas discussões e nas decisões de incidência tecnológica, mormente o modo como ela afecta a produção de conhecimento público, constituindo aquilo a que chamo as epistemologias cívicas dos modernos Estados-nação" (2005: 15).

10 Embora se subscreva parcialmente a perspectiva de Jasanoff, julgamos que, na análise comparativa, será útil recorrer à noção de performação proposta por M. Callon (2006). Segundo Callon: “[...] transpor uma afirmação teórica de um ponto para outro e aplicá-la na prática exige a intervenção de novos actores que contribuam para (ou contrariem) a actualização dos dispositivos sociotécnicos implícitos na afirmação. Só é possível criar, testar, pôr à prova e explorar estes dispositivos sociotécnicos se, para isso, se mobilizarem os engenheiros e os práticos" (2006: 29). É por esse motivo que "quem inova são os colectivos" (2006: 31).

11 O campo do nuclear e da nuclearidade apresenta-se como aquele onde as controvérsias e os debates no espaço público adquirem um carácter mais extremado e, em certos contextos, agonístico. É interessante verificar que D. Nelkin, uma das autoras pioneiras dos estudos das controvérsias científicas e técnicas (1979), tenha precisamente começado por publicar um pequeno estudo sobre o papel dos cientistas e dos técnicos na produção de informação no processo de instalação de uma central de energia nuclear junto do lago Cauyga (Nelkin, 1971). O papel da ciência foi aqui abordado tanto na perspectiva da empresa como do grupo de cidadãos contra a instalação, constituído na sua maioria por cientistas da Universidade de Cornell, localizada bastante próxima da futura central nuclear.

12 No caso dos Estados Unidos, como bem demonstrou J. Masco (2006) a partir do estudo aprofundado do projecto Manhattan, estamos perante um estado de emergência nuclear 
que marca todo o debate sobre a utilização, a aceitação, a contestação ou a rejeição do uso do nuclear para fins civis ou militares. O projecto Manhattan é uma experiência total, que mobilizou os recursos totais do Estado-nação e cujo sucesso transformou os conceitos de natureza, segurança, poder, cidadania e de vivência quotidiana (Masco, 2006: 335).

Como explicitámos na introdução deste artigo, a nuclearidade assume contornos distintos em diferentes contextos nacionais. Em França, F. Zonabend (1993) mostrou de forma magistral como as populações de várias localidades em La Hague (Baixa-Normandia, França) convivem com o nuclear, e como este se insere num projecto de Estado-nação que aspira à independência energética, subsumindo os riscos e exacerbando a capacidade técnica de controlo e de regulação de uma fonte de energia tão perigosa. Na sua abordagem, Zonabend rompeu com os estudos tradicionais sobre as estruturas sociais e a percepção do risco e tentou apreender o efeito da convivência com o nuclear através dos ditos e dos não-ditos, das narrativas e dos silêncios, de paisagens e territórios marcados mas quase invisíveis. Afastando-se das propostas culturalistas e funcionalistas, Zonabend mostrou, a partir das materialidades e das vivências, como a energia nuclear dos discursos oficiais e mediáticos assumiu um carácter quase sagrado, entre o inerte e o animado, o humano e o não-humano, detectando-se uma ansiedade ou um desconforto somente nos silêncios ou nos interstícios das histórias de invulnerabilidade que circulam na esfera pública (1993: 126) ${ }^{7}$. No nosso artigo situamo-nos a montante no processo da nuclearidade, ou seja, na produção primária do urânio empobrecido, e na temporalidade tardia da reconversão e recuperação ambiental das minas e da "redescoberta" do nuclear e seu impacto local nos corpos, nos territórios e nos imaginários: em França, país assumidamente nuclear e uma das maiores potências mundiais na área da produção de energia nuclear, no âmbito de um discurso nacionalista de excepcionalismo nuclear; em Portugal, país semiperiférico e simples fornecedor de urânio empobrecido, onde o discurso sobre o nuclear nunca assumiu contornos de centralidade.

Abordaremos de seguida as temporalidades específicas do urânio em França e em Portugal, começando pelo caso francês.

\section{As temporalidades do urânio na região do Limousin}

Resumindo uma história tão rica quanto complexa, Philippe Brunet (2004) identifica três temporalidades para a exploração do urânio na região do Limousin: o tempo áureo do urânio (1949-1973), o tempo contestado do nuclear (1974-1987) e o tempo incerto da radioactividade (1988-2001).

Em traços gerais, o primeiro período - o tempo áureo do urânio (1949-1973) - corresponde àquele durante o qual, sob a égide do Comissariado para a Energia Atómica, o urânio constitui um bem comum incontestado, participa plenamente do projecto francês de reaquisição de grandeza (Hecht, 2004), e durante o qual a questão ambiental não se coloca. De facto, no contexto de reconstrução material e moral do pós-guerra, a França faz da independência energética nacional um dos factores-chave de mobilização da Nação e do desenvolvimento da tecnologia atómica, da afirmação de uma França tecnológica, um dos meios para a realização desse objectivo (Hecht, 2004; Brunet 2004). A energia atómica implica duas condições indissociáveis: o domínio tecnológico e o domínio do recurso energético, ou seja, o urânio. A contingência de se encontrar urânio na região do Limousin irá alterar o seu porvir, arrancando o território ao seu destino rural. 

o qual as elites regionais procuram renegociar as contrapartidas da exploração de urânio. $\mathrm{O}$ objectivo é o de evitar a dependência do crescimento da região relativamente à exploração mineira (Brunet, 2004: 144). A diferença relativamente ao tempo anterior prende-se com o futuro. Enquanto no tempo áureo do urânio o território procurava apenas uma compensação imediata (impostos, taxas profissionais, etc.), no tempo contestado do nuclear o que as elites regionais procuram é que a exploração de urânio seja acompanhada por um desenvolvimento industrial durável e qualificado (Brunet, 2004: 146).

É neste período que, pelo viés da contestação mais lata ao nuclear, as associações ambientalistas começam a dar visibilidade aos efeitos da actividade mineira de exploração de urânio. Todavia, no decurso do tempo contestado do nuclear, a questão industrial continuará predominante. Incapaz de se desprender das fronteiras dos locais onde se exerce a actividade e fortemente condicionada pela dependência económica dos territórios relativamente à actividade, a questão ambiental continuará, neste período, ainda grandemente marginal (Brunet, 2004: 196).

encerramento das minas no final dos anos 80 e com o fim do ciclo de exploração de urânio em território nacional, à medida que se dissolve a questão industrial afirma-se a questão ambiental. É este o período durante o qual, perante a incerteza relativamente ao legado da exploração para a saúde pública e para o ambiente, a questão ambiental ganha legitimidade e, posteriormente, por via da emergência de novos actores e do processo judicial movido contra a COGEMA, uma nova dimensão.

As questões mais prementes são, agora, a da requalificação e monitorização dos antigos sítios mineiros e a gestão dos resíduos da actividade. Não é mais a questão do urânio como recurso cuja exploração cessou - ou do nuclear como indústria - rompido que foi o elo que, no ciclo do combustível nuclear, a ligava directamente à exploração de urânio -, mas da radioactividade enquanto fenómeno físico portador de riscos sanitários e ambientais e como símbolo de convergência dos dois períodos anteriores.

Dois acontecimentos marcam o tempo incerto da radioactividade contribuindo distintamente para a "redescoberta" da nuclearidade do urânio e para a afirmação da questão ambiental. 0 primeiro, no início dos anos 90 , diz respeito ao projecto de armazenamento de urânio empobrecido em Bessines e ao inquérito público no centro do qual este se encontrou e o segundo, do qual nos ocuparemos adiante mais pormenorizadamente, ao processo judicial que opôs a associação ambientalista SRL à COGEMA.

No tempo incerto da radioactividade confluem, pois, duas incertezas, a incerteza económica resultante do fim da indústria uranífera, mais restrita, e a incerteza da radioactividade, que vai ganhando grandeza à medida que, finda a exploração, se liberta da sua relação directa com uma zona circunscrita de exploração para se estender no espaço (a região, o território nacional), no tempo (as gerações futuras) e nas suas implicações (o ambiente e a saúde pública) ${ }^{8}$. A acção das associações ambientalistas irá, nesta medida, no sentido de obrigar o explorador a permanecer de outro modo no território que explorou.

\section{As temporalidades do urânio na Urgeiriça}

Para a Urgeiriça, na esteira de Phillipe Brunet, propomos igualmente três temporalidades: o tempo tacteante do urânio (1913-1962), o tempo áureo do urânio (1962-1990) e o tempo incerto da radioactividade (1990-2008). As temporalidades aqui definidas não encontram uma 
correspondência directa com a cronologia da exploração e tratamento de urânio na Urgeiriça, assentando a sua formulação, por um lado, no cambiante significado do urânio e, por outro, na ausência, primeiro, e na emergência, depois, da questão ambiental.

Em Portugal, a história do urânio terá começado em 1907, com a descoberta dos primeiros jazigos urano-radíferos ${ }^{9}$. Na Urgeiriça, a aventura do urânio inicia-se em 1913 com a "descoberta de uma pedra pouco vulgar [...] que exames revelaram possuir elevado teor de urânio" (Veiga, 2006: 257). A descoberta ocasional de jazigos urano-radíferos na Urgeiriça deram, de facto, no princípio do século $\mathrm{XX}$, origem a uma indústria votada inicialmente à produção de concentrados de rádio e, posteriormente, de urânio. De 1913 a 2001, a exploração e o tratamento de rádio e, posteriormente, de urânio serão da responsabilidade da Henry Burnay \& C.. (1913-1931), da Companhia Portuguesa de Radium, Lda. (1932-1962), da Junta de Energia Nuclear (1962-1977), da Empresa Nacional de Urânio, EP (1977-1990) e, finalmente, da Empresa Nacional de Urânio, SA (1990-2001).

O tempo tacteante do urânio (1913-1962) corresponde ao arranque da exploração e estendese até à interrupção da actividade privada no sector da exploração de minérios de urânio, com os bens, concessões e direitos da Companhia Portuguesa de Radium a serem transferidos para o Estado português, que passará a exercer essa actividade em regime de monopólio. O tempo da Companhia Portuguesa de Radium, apesar de tacteante em relação ao significado do urânio, corresponde a um período de crescimento de infraestruturas industriais, como a construção de casas para empregados e para operários, de um campo de jogos, de um parque infantil, de um balneário, etc. $O$ urânio constitui, nesse período, um bem para aqueles que o exploram e para os trabalhadores que neste alicerçam as suas vidas. A nível local, os benefícios da exploração, à excepção da localidade da Urgeiriça, são quase nulos, situação que, aliás, do ponto de vista de diversos actores locais por nós entrevistados, se manterá independentemente da temporalidade considerada.

A questão ambiental não se coloca durante o tempo tacteante do urânio, tal como acontece no período seguinte: o tempo áureo do urânio (1962-1990). Na transição entre um período e o outro encontra-se, em nossa opinião, um elo fundamental: a Junta de Energia Nuclear $(J E N)^{10}$. Será, de facto, a partir da instalação da JEN, em 1954, que o urânio, do ponto de vista político como do ponto de vista de uma elite emergente de técnicos, engenheiros, cientistas e académicos, ganhará relevo nas aspirações do país tanto a nível nacional como internacional (Taveira, 2005).

Finalmente, o tempo incerto da radioactividade (1990-2008) corresponde, tal como acontece na região do Limousin, ao último fôlego da exploração de urânio e à afirmação da questão ambiental. Neste período aparecem como relevantes a transição da Empresa Nacional de Urânio, EP. para Empresa Nacional de Urânio, SA (Decreto-Lei n.. 376/90, de 30 de Novembro de 1990), o encerramento da Oficina de Tratamento Químico da Urgeiriça, o início da redução de efectivos da empresa e a inauguração, em 2008, dos trabalhos de requalificação da Barragem Velha de Rejeitados, que assumimos, no quadro da análise, como um momento de tentativa de encerramento da contestação local por parte do Estado.

28 Em 1990, quando a Empresa Nacional de Urânio, SA. assume a gestão do complexo industrial da Urgeiriça, o tempo é de crise e de reestruturação. Depois de ensaiadas infrutiferamente diversas estratégias de diversificação da actividade (pedreiras, rochas ornamentais, etc.), em Março de 2001, é decidido em Assembleia-Geral o início do 
processo de dissolução e entrada em liquidação da empresa, processo este que coincide com a implementação do enquadramento jurídico português que sustenta a recuperação ambiental de áreas sujeitas à actividade mineira, nomeadamente o Decreto-Lei n. ${ }^{\circ}$ 198A/2001, que representa um marco importante na medida em que fornece um sólido fundamento jurídico e político à missão da qual a Empresa de Desenvolvimento Mineiro (EDM) foi incumbida pelo Estado: a recuperação ambiental de antigas áreas mineiras degradadas, com vista à sua reabilitação e valorização económica. Isto permite à EDM posicionar-se numa esfera relativamente à qual todo o resto, tudo o que escapa à sua missão, pode ser classificado como lhe sendo estranho, ao mesmo tempo que, como se verá, lhe permite assumir posições de força relativamente a determinados aspectos que entravam o cumprimento dessa missão $0^{11}$.

\section{0 processo judicial contra a COGEMA}

29 No Limousin, como de resto acontece na Urgeiriça, a "redescoberta" da nuclearidade dos antigos sítios mineiros coincide com o fim da actividade. Antes, porém, que cessasse a exploração diversas associações locais começaram a exprimir um sentimento de desconfiança relativamente à COGEMA e aos poderes públicos responsáveis pela monitorização da sua acção. Nos anos 70 e 80 surgem as primeiras polémicas mediáticas, com a denúncia pelas associações ambientalistas do depósito no Limousin de resíduos radioactivos provenientes de instalações exteriores. No entanto, será necessário esperar pelo início dos anos 90 para ver as polémicas ganharem dimensão à medida que se sucedem os relatórios de avaliação dos impactes da actividade mineira no território e, nomeadamente, no meio aquático da região.

Apoiando-se nos diagnósticos à actividade da COGEMA que vinham sendo realizados por diversos organismos estatais e independentes e apostada em perturbar o regime de excepção no qual a empresa vinha operando, em Março de 1999, a associação Sources et Rivières de Limousin (SRL) apresenta uma queixa perante o juiz de instrução do Tribunal de Grande Instância de Limoges contra a COGEMA por poluição, abandono de resíduos e colocação em perigo de outrem. O juiz ouve, então, a SRL, convoca a presidente da COGEMA, Anne Lauvergeon, e as administrações implicadas: a Direcção Departamental dos Assuntos Sanitários e Sociais (Direction Départementale des Affaires Sanitaires et Sociales, DDAS) ${ }^{12}$ e a Direcção Regional da Indústria, Investigação e Ambiente da Região Limousin ( Direction Régionale de l'Industrie, de la Recherche et de l'Environnement, DRIRE) ${ }^{13}$.

31 Não sendo este o espaço para analisar em pormenor o processo judicial ${ }^{14}$, procuraremos salientar dois aspectos que nos parecem particularmente relevantes. Primeiro, o facto de ao longo de todo o processo, se tornar patente o interesse do Estado em não deixar o caso ganhar dimensão, o que levanta a questão do excepcionalismo do nuclear em França. Segundo, o modo como a argumentação científica - num caso em que é notória a desigualdade de armas - apesar de obstaculizar uma eventual condenação da COGEMA, abrir espaço à incerteza e, consequentemente, à expansão do espaço agonístico.

\subsection{0 caso COGEMA}

Composta quase exclusivamente por professores de Direito Ambiental e de Economia do Ambiente da Universidade de Limoges, a SRL procura o advogado Alexandre Faro, especializado em Direito Ambiental, e com este define a melhor estratégia do processo. 

ter sido um erro, Alexandre Faro e a SRL optam pelo penal. Subjacente a esta opção encontra-se, por um lado, uma particularidade do sistema jurídico francês e, por outro, a ausência de recursos materiais da associação. Iniciando um procedimento cível contra a COGEMA por poluição das águas, o encargo com a necessária e onerosa peritagem técnica ficaria a cargo da associação, enquanto, no caso de se tratar de um procedimento penal, estes encargos seriam assumidos pelo Estado. Embora a associação dispusesse de diversas avaliações técnicas, a queixa é apresentada tendo por base, no essencial, as peritagens prévias realizadas pela independente Comissão de Pesquisa e Informação Independentes sobre a Radioactividade (Commission de Recherche et d'Information Indépendantes sur la Radioactivité, CRII-RAD) ${ }^{15}$ a pedido do Conselho Geral do Departamento da Haute-Vienne. Depois de apresentada a queixa, durante cerca de um ano, o juiz de instrução revela-se "pouco sensível à questão" (entrevista a Alexandre Faro, Advogado SRL, 07.01.2009). Environement, FNE) que se constitui como parte civil do processo e, em Setembro de 2002, depois de mais de três anos desde o início do processo, o juiz de instrução de Limoges, Gérard Biardeaud, decide chamar a COGEMA. Começam, então, a surgir os primeiros entraves. Primeiro, com a análise pericial e aqui "o sistema é um bocado perverso, já que o juiz nos disse, oficiosamente, que, caso acedesse ao nosso pedido de peritagem, todo o seu orçamento, todo o orçamento do tribunal para peritagens seria gasto nisso" (entrevista a Alexandre Faro, idem). Na altura, a estratégia passa por não afrontar directamente um juiz que, finalmente, mostrava alguma receptividade relativamente ao caso, e "essa terá sido, talvez, a nossa principal fraqueza. Acabei por aceitar que não houvesse uma peritagem. No final, pagámos caro essa fraqueza" (entrevista a Alexandre Faro, idem). Depois, passa pela acção directa do Procurador da República junto do Tribunal de Grande Instância de Limoges que requer a não-pronúncia da COGEMA relativamente aos crimes acusados com base num relatório da Direcção Regional da Indústria, Investigação e Ambiente da Região Limousin que desresponsabiliza a COGEMA. ${ }^{16}$ Porquê?

É o nuclear! O nuclear, em França, é o nuclear. É o Estado no Estado. [...] A estratégia do nuclear em França é simples: escondem-se por detrás de um regime de autorização, escondem-se por detrás da autoridade do Estado. Mesmo sendo, supostamente, a AREVA uma sociedade de direito privado, na realidade quando existe um contencioso contra a AREVA, quando a AREVA começa a enfrentar dificuldades, solicita e obtém a intervenção do Estado. [...] Habitualmente, nos casos de procedimentos cíveis não se vê o Ministério Público ou o Procurador intervir, mas neste caso o Procurador da República esteve presente em todas as audiências e sempre para sustentar a posição que as nossas exigências não tinham cabimento, que não tínhamos razão, etc. [...] Isto só para lhe dizer o quanto o Estado se interessa por todas as questões que envolvam o nuclear. (Entrevista a Alexandre Faro, idem)

Jacques Blanquet, da Associação Nacional para a Proteç̧ão das Águas e Rios (Association Nationale pour la Protection des Eaux et Rivières, ANPERTOS) ${ }^{17}$, revela-se mais crítico, apontando como principal entrave a uma eventual condenação da COGEMA a estratégia adoptada pela acusação que envereda pela prova da radioactividade e "perde" o processo devido a um preciosismo jurídico. A ideia sustentada pelo ambientalista é a de que a intromissão de peritos acabou por se revelar nefasta para o processo. Para ele, a argumentação das associações deveria acentuar os impactos sociais negativos e de largo espectro do nuclear e dos seus resíduos. 

limites mínimos, etc.), o processo entra num domínio no qual a COGEMA está mais bem equipada para rebater, para fazer prova, para, em suma, manusear a nuclearidade. A voz da ciência sobrepõe-se a todas as outras e a linguagem da ciência passa a definir o tom do processo, ganhando vantagem aqueles que mais recursos detêm para a ela recorrerem. No dia 13 de Maio de 2003, o juiz de instrução pronunciou a CocemA pelos crimes de abandono de resíduos e de poluição de águas e remete o julgamento deste grupo industrial para o Tribunal Correccional de Limoges. Nesse mesmo dia, é o próprio Procurador da República quem recorre dessa decisão para a Câmara de Instrução do Tribunal de Recurso de Limoges. A COGEMA continua a sustentar a sua defesa nos controlos realizados pela Direcção Regional da Indústria, Investigação e Ambiente da Região Limousin, no respeito pela regulamentação em vigor e pelos regulamentos da prefeitura, na ausência de nexo de causalidade e na falta do elemento intencional ${ }^{18}$.

A 26 de Março de 2004, a Câmara de Instrução do Tribunal de Recurso de Limoges profere um acórdão histórico contra a COGEMA, confirmando o envio do processo para o Tribunal Correccional. No dia 30 de Março de 2004, último dia do prazo legal para o fazer, a COGEMA recorre para o Tribunal de Cassação do acórdão proferido pelo Tribunal de Recurso de Limoges, que, todavia, rejeita o recurso apresentado por esta, confirmando a decisão do Tribunal de Recurso no sentido de apresentar a COGEMA a julgamento.

No dia 25 de Junho de 2005, seis anos após a queixa da SRL, tem assim lugar o primeiro julgamento contra a COGEMA num caso ambiental. Apesar das expectativas geradas pelo processo, no dia 14 de Outubro de 2005, tendo em conta a imprecisão da lei relativamente à noção de radioactividade susceptível de desencadear a aplicação de sanções penais, o Tribunal Correccional decide pela absolvição da COGEMA. As partes cíveis do processo recorreram desta decisão para o Tribunal de Recurso de Limoges que, chamado a pronunciar-se somente sobre a parte civil do processo, em Junho de 2006, confirma a absolvição da COGEMA. As associações decidem não recorrer ao Tribunal de Cassação, simplesmente porque "o direito ambiental não se aplica à COGEMA que beneficia de um regime de excepção inerente ao direito particular que enquadra a radioactividade em França" ${ }^{19}$.

40 E, porém, o simples facto de a COGEMA ter respondido em Tribunal por delitos de poluição é considerado pelas associações ambientalistas como uma vitória. Num comunicado de imprensa de 28 de Junho de 2006, a SRL e a FNE declaravam não ter sido vã a "guerrilha judicial" contra a COGEMA, na medida em que contribuiu para acelerar a consciência dos poderes públicos para a seriedade do legado deste grupo industrial para as gerações futuras da região Limousin.

41 Acompanhando o movimento de montée en grandeur da questão ambiental, o processo contra a COGEMA é perspectivado como uma ruptura, por um lado, com o contrato que sempre colocou o território sob a alçada do grupo e, por outro, com a impunidade que sempre ditou o comportamento do mesmo relativamente ao território. Partindo ao assalto desta "fortaleza", as associações ambientalistas sabiam-se derrotadas à partida, mas sabiam igualmente que a litigação jurídica era a sua melhor arma, não para ganhar, mas para provocar alterações nos dispositivos de gestão do passivo ambiental, para alterar políticas e ganhar voz num domínio que foi sempre sujeito ao silêncio da COGEMA.

A absolvição da COGEMA não encerra a controvérsia em torno dos impactos ambientais da sua actividade e da radioactividade no território. Pelo contrário, expande-a, torna-a

Configurações, 8 | 2013 
acessível a um conjunto de novos actores, que se vinham revelando com a afirmação e legitimação da questão ambiental (Brunet, 2004), agora com poderes renovados resultantes da fissura aberta pelo processo judicial no excepcionalismo do nuclear. 0 "caso COGEMA", inscrevendo-se claramente no processo de continuidade da afirmação da questão ambiental, permitiu à SRL interpor-se no contrato entre o território e a COGEMA herdado do tempo áureo do urânio, ganhar respeitabilidade e afirmar-se como um interlocutor incontornável em dois órgãos de vigilância e monitorização da actividade passada, presente e futura da COGEMA, agora AREVA, NC: a Comissão Local de Informação e Vigilância (CLIS), de nível local ${ }^{20}$, e o Grupo de Peritagem Pluralista das Minas do Limousin (GEP), este de nível nacional ${ }^{21}$.

\section{A requalificação ambiental da Urgeiriça}

No tempo incerto da radioactividade, também na Urgeiriça uma nova ordem de preocupações passa a ocupar o primeiro plano: "a poluição derivada de cortas, galerias e escombreiras abandonadas; as sequelas deixadas pelos acidentes e doenças profissionais; [e] a situação das localidades fortemente marcadas pela presença de empresas concessionárias que suspenderam ou encerraram a laboração" (Nunes e Alves, 2004: 472). Se estas questões se colocam à generalidade do sector mineiro português, no caso das minas onde se exploraram minérios radioactivos assumem, porém, maior premência (Santos Oliveira et al., 1999).

44 A partir de 2001 estavam já reunidas as condições - uma profusão de estudos, um enquadramento legal e a concessão dos trabalhos a uma empresa pública - para dar cumprimento ao Programa de Recuperação Ambiental das Áreas Mineiras Degradadas e, concretamente, para avançar com a remediação das situações mais prementes, entre as quais se encontra a barragem de rejeitados da Urgeiriça (Barragem Velha). Os trabalhos de Estabilização de Taludes, Selagem e Drenagem da Barragem Velha de Rejeitados da Mina da Urgeiriça terão início apenas em 2006 e serão inaugurados em 2008. No período compreendido entre a aprovação do Decreto-Lei n.․ 198-A/2001 e a inauguração dos trabalhos da Barragem Velha, entre 2001 e 2008, portanto, o território não permanece neutro.

No espaço agonístico complexo já existente e em formação a nível local, diversos actores levarão a cabo acções de protesto e actos públicos visando: $i$ ) os efeitos associados à actividade de exploração e tratamento de urânio no território (a questão ambiental); ii) questões tangenciais à requalificação ambiental (condições de habitabilidade do parque habitacional da ENU e a restauração do concelho de Canas de Senhorim, por exemplo) (Mendes e Araújo, 2010); e a questão de que trataremos aqui e que se prende com iii) os direitos sociais e laborais dos Antigos Trabalhadores da Empresa Nacional de Urânio (ENU). As reivindicações destes últimos - a realização de exames médicos, a equiparação a trabalhadores de fundo de mina para efeitos de benefícios na idade da reforma, e as indemnizações às viúvas dos mineiros já falecidos - irão encontrar num estudo epidemiológico, na doença e na morte fortes aliados na produção de um efeito mediático no sentido de expandir o âmbito da responsabilidade e de responsabilização do e pelo Estado que este, por sua vez, procurará confinar à questão ambiental, ou seja, à requalificação das minas da Urgeiriça.

Também aqui a voz da ciência é importante para abrir espaço à incerteza (Borraz, 2011), mas, contrariamente àquilo que acontece no Limousin, da ciência os trabalhadores e os 
seus representantes retêm apenas os elementos que podem mobilizar para permitir que, por um processo de extensão e de analogia, a nuclearidade se infiltre nos corpos como um modo de os trabalhadores se igualizarem ao território e de, por essa via, serem também eles objecto de um tratamento especial, de um tratamento devido. Cabe referir que desde o início os trabalhadores contestaram a sua não-inclusão explícita como subamostra no estudo epidemiológico, reivindicando um estudo específico de avaliação da sua exposição à radioactividade durante o seu trajecto profissional e os possíveis impactos intergeracionais dessa exposição.

Inicialmente concebido com o intuito de tranquilizar a população de Canas de Senhorim relativamente aos riscos efectivos que representa o legado da exploração de urânio, ou seja, relativamente à nuclearidade do território, o estudo epidemiológico terá um efeito inesperado ao fundamentar a reivindicação de direitos sociais e laborais por parte dos trabalhadores da ENU numa base nova: a dos corpos contaminados.

\subsection{0 estudo epidemiológico e os Antigos Trabalhadores da ENU}

48 Em Abril de 2003, dando resposta à Resolução da Assembleia da República n.․ 34/2001, o Instituto Nacional de Saúde Dr. Ricardo Jorge (INSA) é encarregado pelo Governo (XV GC, Durão Barroso, PSD) de coordenar "a realização de estudos que [identifiquem] as eventuais repercussões das minas de urânio e seus resíduos, no ambiente e na saúde das populações a elas expostas" (INSA, 2005: 3).

O estudo epidemiológico, denominado MinUrar, toma à letra a Resolução e, "face à impossibilidade de estudar os eventuais efeitos associados a todas as minas de urânio" (INSA, 2005: 3), centra-se exclusivamente na comunidade local de Canas de Senhorim. O pioneirismo do MinUrar reside, inclusivamente, em abordar os efeitos aos quais as populações que vivem próximo das minas de urânio estão sujeitas e os efeitos que as escombreiras de minas de urânio e as lagunas com águas residuais ácidas ricas em metais pesados exercem sobre a saúde dessas populações, já que, relativamente aos trabalhadores, estes efeitos parecem sobejamente estabelecidos e incontestáveis ${ }^{22}$.

Apesar de o estudo MinUrar não estabelecer de forma inequívoca uma relação causal entre a exploração de urânio e a incidência aumentada de neoplasias malignas para a população de Canas de Senhorim, assume um papel preponderante no modelar da futura luta dos Antigos Trabalhadores da ENU, para quem essa relação, apesar de o estudo não lhes ser dirigido, passa a ser creditada pela ciência e, no âmbito da sua estratégia de acção, um suporte fundamental à enfatização da nuclearidade do urânio e, consequentemente, dos seus efeitos. Das incertezas do MinUrar o que os Antigos Trabalhadores irão reter, para melhor hiperbolizar ou enfatizar através dos media, é a certeza de uma relação entre trabalho na ENU e neoplasias malignas, abrindo desta forma caminho à entrada de outras questões relativamente às quais o Estado terá de assumir responsabilidade senão pela força da Lei então por uma questão moral. É a dimensão social, e não técnica, o interesse humano, e não o risco para a saúde pública, que atraem a atenção dos media (Sandman, 1994; Delicado et al., 2007), facto que os Antigos Trabalhadores serão céleres em compreender, mantendo uma relação com a comunicação social que se poderia classificar de recíproca.

51 Ao contrário do que acontece em muitas controvérsias para as quais a ciência é convocada na avaliação do risco $^{23}$ - nomeadamente, no caso francês, no qual a ciência é continuamente convocada e contestada -, na Urgeiriça os resultados do MinUrar nem são 
contestados, nem se verifica qualquer recurso a contraperitos para fornecer uma interpretação alternativa ou não "oficial". Recorrendo à terminologia utilizada por J. Arriscado Nunes (2007: 51) para descrever os modos de envolvimento dos cidadãos com a ciência, o que se verifica é um "alinhamento" com os resultados do estudo, uma apropriação do MinUrar - e não especificamente dos seus resultados - por parte dos trabalhadores para melhor os incorporar. A aceitabilidade do risco associada ao trabalho na Urgeiriça dá lugar a uma aceitação do risco desde que este contenha e permita aos trabalhadores veicular uma nova imagem de si mesmos: a de corpos contaminados. Uma imagem concordante com a do território contaminado, relativamente ao qual foram assumidas pelo Estado medidas de reparação.

Para os Antigos Trabalhadores da ENU, na sequência do encerramento da actividade do complexo industrial da Urgeiriça e, mais expressivamente, após o estudo epidemiológico, a relação causa-efeito entre trabalho na ENU e riscos para a saúde passa a ser incontestável e, no âmbito da sua estratégia de acção, um suporte fundamental à enfatização da ameaça do urânio, à nuclearidade do urânio. Encontrando na dramatização dos efeitos para a saúde e na morte fortes aliados na produção de um efeito mediático ${ }^{24}$, os ex-trabalhadores encontram no processo de requalificação visibilidade para questões que não têm, apesar de sustentadas nos efeitos da radioactividade, a saúde como principal factor aglutinador.

53 Na sequência de diversas acções de protesto por parte dos trabalhadores, no dia 15 de Dezembro de 2004, o Conselho de Ministros aprova o Decreto-Lei n.. 28/2005, que concede a equiparação de fundo de mina aos trabalhadores que, à data da dissolução da ENU, mantinham um vínculo profissional com a empresa, ou seja, cerca de quarenta trabalhadores de um total de cerca de quatrocentos. A partir deste momento, a referência aos "Actuais e Antigos Trabalhadores da ENU" deixa de fazer sentido, restringindo-se agora o colectivo aos "Antigos Trabalhadores da ENU". O Decreto-Lei n.․ 28/2005 não só concorre para a implosão do colectivo dos trabalhadores da ENU, como, principalmente, adiciona ao enquadramento do protesto - antes sustentado na "redescoberta" da nuclearidade e das suas implicações (a doença e a morte) - dois elementos que suplantam os restantes: a injustiça e o ressentimento.

54 Na acção dos Antigos Trabalhadores da ENU, o que aparece como o elemento mais saliente é o recurso à enfatização dos efeitos para a saúde associados ao trabalho no complexo industrial da Urgeiriça e não os efeitos em si com o objectivo de estender as medidas de reparação propostas pelo Estado a outros domínios que se situam necessariamente fora do âmbito da requalificação ambiental, mas que são conexas à actividade da ENU no território. Reclamam-se, tal como é reconhecido ao território, como contaminados.

Ao contrário do que acontece em França - com a ampliação da incerteza e a desterritorialização da nuclearidade -, na Urgeiriça a corporalização da nuclearidade funciona simultaneamente como um factor de territorialização da nuclearidade impedindo que extravase as suas fronteiras espaciais (dos antigos sítios mineiros para o conjunto do território) e temporais (do passado para as gerações futuras). 0 processo de requalificação ambiental serve, nesta medida, de amplificador para a reivindicação de questões que não têm os efeitos para a saúde como principal factor aglutinador, mas sim o ressentimento e a injustiça originados pelo Decreto-Lei n. 28/2005. Os Antigos Trabalhadores investem fortemente numa interpretação alinhada e comprometida dos resultados do estudo epidemiológico que visa, acima de tudo, legitimar as reivindicações 
de direitos não inscritos na proposta de reparação para o território apresentada pelo Estado, ou seja, a requalificação ambiental ${ }^{25}$.

\section{Considerações finais}

56 A partir de dois estudos de caso, marcados por eventos distintos mas ancorados em materialidades similares, a análise dos efeitos no ambiente e na saúde da nuclearidade da actividade de exploração do urânio permitiu-nos identificar as dinâmicas das controvérsias presentes em França e em Portugal e o papel da ciência na esfera pública e nas políticas públicas.

A cultura política em França, marcada por uma longa história de movimentos sociais e por uma esfera pública crítica, propiciou um contexto de contestação à indústria mineira e aos passivos ambientais e uma luta de causas que passou por uma desterritorialização dos efeitos da nuclearidade visando a responsabilização administrativa do Estado e a perturbação do contrato vigente entre território, população e nuclearidade. Assim, em França, o evento desencadeador, as controvérsias ocorridas, a mobilização da sociedade civil e as peritagens técnicas convergiram num processo de litigação enquadrado no campo tradicional e mais abrangente do activismo ambiental e dos reportórios de aç̧ão antinucleares.

O affaire em França conduziu a uma reestruturação sociotécnica reactiva, com a criação de um Grupo de Peritagem Pluralista e de uma Comissão Local de Informação e Vigilância, nas quais a SRL passa a marcar presença e a ter voz, com a consagração de regras rigorosas e com uma mudança no regime de regulação e de vigilância das actividades da AREVA e da fileira nuclear. O excepcionalismo nuclear da França foi circunscrito e limitado pelos direitos de cidadania ambiental, um processo orientado para a mudança das políticas públicas. Abrira-se uma brecha no contrato tácito entre o território, o Estado e o nuclear, por intermédio da incerteza da radioactividade, e era possível expandir a controvérsia em torno dos impactos ambientais das actividades da empresa francesa do nuclear, tornando-a acessível a um conjunto de novos actores e obviando ao excepcionalismo do nuclear. Se as peritagens e os dados científicos permitiram a vitória judicial da empresa do nuclear, o acesso ao conhecimento e os novos conhecimentos mobilizados permitiram uma mudança e uma nova configuração dos dispositivos de regulação e de governação associados à questão nuclear e à radioactividade.

Em Portugal, os mineiros e os trabalhadores lutaram para expandir o âmbito restrito da intervenção ambiental, de forma a incorporar os direitos sociais e laborais. Através dos corpos contaminados procurou-se invocar a emoção e as questões éticas, afectando os políticos e a opinião pública, mas sem que se produzisse cidadania ou universalidade. A controvérsia permaneceu, deste modo, confinada a um espaço local e a grupos circunstanciais, incapazes de mobilizar peritos independentes ou movimentos sociais não locais. As reivindicações basearam-se não em argumentos técnicos, mas sim na emoção, no sofrimento, na morte, no ressentimento e em corpos que momentaneamente se tornaram visíveis na esfera pública. Contudo, esses corpos só puderam assumir o estatuto de contaminados e adquirir valor mediático, através da apropriação pelos extrabalhadores e das suas estruturas representativas dos resultados do estudo epidemiológico da população que habitava na zona de influência das minas de urânio. 
60 A posição de Portugal na semiperiferia nuclear, como um mero produtor de matériaprima no mercado global do urânio, permitiu o confinamento da controvérsia, a proeminência das narrativas oficiais e a hegemonia dos peritos oficiais. Os acontecimentos e os protestos locais não resultaram numa reestruturação sociotécnica, desenrolando-se a lógica e o mercado da reabilitação ambiental sem grandes contratempos. Em Portugal, os trabalhadores, ao tornarem-se visíveis como corpos contaminados, procuraram desviar o Estado de um posicionamento meramente técnico para uma tomada de posição moral e ética, convocando para o efeito os dados objectivos de um estudo epidemiológico que mostrava associação entre radioactividade e potenciais efeitos nefastos nas populações expostas. Os corpos contaminados posicionam as consequências da exploração de urânio no aqui e no agora e procuram uma resposta por parte do Estado, moral mais do que técnica, igualmente circunscrita a esse espaço, a esse tempo e, principalmente, para esses corpos.

61 Com o encerramento das minas, em ambos os casos os trabalhadores partilharam a perda dos empregos, agravada em Portugal pelo ressentimento e o sentimento de injustiça. A redescoberta da nuclearidade nestes territórios ocorreu, como se viu, de formas distintas, mas a análise da controvérsia permite-nos afirmar que, em ambos os casos, o processo de normalização decorreu sem mudanças significativas ou reconfiguração dos direitos de cidadania. Os territórios do urânio foram abordados como desafios técnicos: em França, no contexto do seu excepcionalismo nuclear e com a presença de corpos difusos (porque associados às gerações vindouras e não aos trabalhadores mineiros) e de um território expandido (porque associado ao conjunto do território nacional e não aos antigos sítios mineiros), com a implementação de controlos administrativos mais rigorosos e um regime de regulação mais bem codificado; em Portugal, com a presença hiperbólica de corpos confinados a um espaço delimitado e sem mudanças relevantes a nível da regulação.

62 Tanto em França como em Portugal os acontecimentos resultaram na normalização dos processos sociais relacionados com a exploração do urânio e a nuclearidade. Em duas culturas políticas distintas, as nuclearidades da França e de Portugal normalizaram os acontecimentos e os protestos em torno da exploração do urânio e da reabilitação das áreas afectadas pelos resíduos contaminados, sem incorporarem, sem reconhecerem nada para além das performações sociotécnicas e das suas inerentes materialidades, simbolismos e práticas. Na região do Limousin e na Urgeiriça testemunhamos a plena presença e a coerção do Estado, o funcionamento integral do mercado e a biopolítica do regime de regulação do urânio.

63 Consideramos, assim, na esteira de A. Badiou (2006), que em França e em Portugal as questões de cidadania permaneceram invisíveis no que concerne à nuclearidade, aventadas somente nos interstícios da política e das performações sociotécnicas. As inovações colectivas, mais presentes no caso da França, mantiveram à distância as questões em torno da cidadania. Se a emergência do Limousin e da Urgeiriça como territórios nucleares está bem documentada, as memórias pessoais e colectivas que se recompõem e são incluídas nas novas narrativas não produzem novos sujeitos políticos, novas e alternativas formas de estar no território, de pertencer, com plenos direitos e preparados para o futuro. 


\section{BIBLIOGRAPHY}

BADIOU, Alain (2006), Logiques des mondes: L'Être et l'événement, 2. Paris: Seuil.

BARTHE, Yannicke (2006), Le Pouvoir d'indécision. La Mise en politique des déchets nucléaires, Paris, Economica.

BATISTA, M. J. et al., (2005), "Preliminary results of a risk assessment study for uranium contamination in central Portugal", in IAEA (2005), Environmental Contamination from Uranium Production Facilities and their Remediation. Proceedings of an International Workshop on Environmental Contamination from Uranium Production Facilities and their Remediation, organized by the International Atomic Energy Agency, Lisbon, 11-13 February 2004. Vienna: International Atomic Energy Agency, 17-28.

BATISTA, M. J. et al. (2004), "Preliminary results of a risk assessment study for uranium contamination in central Portugal", Paper presented at the International Workshop on Environmental Contamination from Uranium Production: Facilities and remediation measures, ITN/ DPRSN, Lisboa, 11-13 February 2004.

BENTO, Sofia (2006), La Difficile existence du barrage d'Alqueva: Une ethnographie des démonstrations sociotechniques. Tese de doutoramento. Lisboa, Instituto Superior de Economia e Gestão da Universidade Técnica de Lisboa e École Nationale Supérieure de Mines de Paris.

BORRAZ, Olivier (2011), "From risk to the government of uncertainty: the case of mobile telephony”, Journal of Risk Research, 14(8), 969-982.

BORRAZ, Olivier (2008), Les Politiques du risque, Paris, Presses de Sciences Po.

BRUNET, Philippe (2004), La Nature dans tous ses États. Uranium, nucléaire et radioactivité en Limousin, Limoges, Presses Universitaires de Limoges.

CALLON, Michel (2006), "What does it mean to say that economics is performative?", CSI Working Papers Series, 5, Paris, CSI-ENSMP.

COSTA, Luís Rodrigues da (2000), “A recuperação ambiental de áreas mineiras degradadas nas políticas de integração da indústria e ambiente do Ministério da Economia”, Boletim de Minas, 37 (3), 167-171.

DELICADO, Ana et al. (2007), "Informação ou dramatização do risco: os media e os novos riscos", in GONÇALVES, Maria Eduarda (coord.) et al., Os Portugueses e os Novos Riscos, Lisboa, ICS, 217-244.

GONÇALVES, Maria Eduarda (2007a), “A política do risco: Entre gestão de crises e regulação de processos”, in GONÇALVES, Maria Eduarda (coord.) et al., Os Portugueses e os Novos Riscos, Lisboa, ICS, 139-167.

GONÇALVES, Maria Eduarda (2007b), “Consumidores, pacientes, activistas, cidadãos: Representação e participação do público na gestão do risco", in GONÇALVES, Maria Eduarda (coord.) et al., Os Portugueses e os Novos Riscos, Lisboa, ICS, 169-215.

GONÇALVES, Maria Eduarda et al. (2007), "Entre incertezas e divergências: A ciência e a avaliação do risco", in GONÇALVES, Maria Eduarda (coord.) et al., Os Portugueses e os Novos Riscos, Lisboa, ICS, 107-137. 
GRANJO, Paulo (2004), Trabalhamos sobre um Barril de Pólvora. Homens e perigo na refinaria de Sines, Lisboa, ICS.

HECHT, Gabrielle (2009), "Africa and the Nuclear World: Labor, occupational health, and the transnational production of uranium", Comparative Studies in Society and History, 51(4), 896-926.

HECHT, Gabrielle (2006), "Nuclear ontologies”, Constellations, 13(3), 320-331.

HECHT, Gabrielle (2004), Le Rayonnement de la France. Énergie nucléaire et identité nationale après la seconde guerre mondiale, Paris, La Découverte.

INSTITUTO NACIONAL DE SAÚDE DR. RICARDO JORGE (INSA) (Junho 2005), Minas de Urânio e Seus Resíduos: Efeitos na saúde da população, Relatório Científico I, Lisboa, INS/ ONSA.

INSTITUTO NACIONAL DE SAÚDE DR. RICARDO JORGE (INSA) (Fevereiro 2007), Minas de Urânio e Seus Resíduos: Efeitos na saúde da população, Relatório Científico II, Conclusões e recomendações do projecto MinUrar, Lisboa, INS/ONSA.

JASANOFF, Sheila (2005), Designs on Nature. Science and democracy in Europe and the United States, Princeton, Princeton University Press.

JERÓNIMO, Helena (2010), Queimar a Incerteza. Poder e ambiente no conflito da co-incineração de resíduos industriais perigosos, Lisboa, Imprensa de Ciências Sociais.

KINCHY, Abby; KLEINMAN, Daniel; AUTRY, Robyn (2008), “Against free markets, against science? Regulating the socio-economic effects of biotechnology”, Rural Sociology, 73(2), 147-180.

LATOUR, Bruno (2005), "From realpolitik to dingpolitik, or How to make things public", em Bruno Latour e Peter Weibel (eds.), Making Things Public: Atmospheres of Democracy, Cambridge, MIT Press, 14-31.

LATOUR, Bruno (2004), "Why has critique run out of steam? From matters of fact to matters of concern”, Critical Inquiry, 30, 225-248.

LERIDON, Alain (2009), L'Atome hexagonal: Histoire de la relation de la France avec le nucléaire, Lyon, Aléas.

MASCO, Joseph (2006), The Nuclear Borderlands: The Manhattan Project in Post Cold-War New Mexico, Princeton, Princeton University Press.

MATIAS, Marisa (2009), A Natureza Farta de Nós? Ambiente, saúde e formas emergentes de cidadania, Tese de doutoramento, Coimbra, Faculdade de Economia da Universidade de Coimbra.

MENDES, José Manuel; ARAGÃo, Alexandra; ARAÚJO, Pedro; NOBRE, Márcio (2010), Risco, Cidadania e Estado num Mundo Globalizado, Relatório de investigação, Coimbra, Centro de Estudos Sociais.

MENDES, José Manuel; ARAÚJO, Pedro (2010), “Nuclearidade, trabalho dos corpos e justiça: A requalificação ambiental das minas da Urgeiriça e os protestos locais", Sociologia-Problemas e práticas, 64, 81-105.

MUKERJI, Chandra (2009), Impossible Engineering: Technology and Territoriality on the Canal du Midi, Princeton, Princeton University Press.

MUKERJI, Chandra (2007a), “Controversy studies”, em George Ritzer (ed.), The Blackwell Encyclopedia of Sociology, Oxford, Blackwell Publishing.

MUKERJI, Chandra (2007b), "Stewardship politics and the control of wild weather: Levees, seawalls, and state building in 17th-Century France", Social Studies of Science, 37(1), 127-133. 
NELKIN, Dorothy (1995), "Science controversies: the dynamics of public disputes in the United States”, em Sheila Jassanoff, G. E. Markle, J. C. Peterson, Trevor Pinch (eds.), Handbook of Science and Technology Studies, Thousand Oaks, Sage, 444-456.

NELKIN, Dorothy (ed.) (1979), Controversy: Politics of Technical Decision, Beverly Hills, Sage.

NELKIN, Dorothy (1971) Nuclear Power and its Critics: The Cayuga Lake controversy, Ithaca, NY, Cornell University Press.

NUNES, João Arriscado (2007), Governação, Conhecimentos e Participação Pública. Provas de Agregação apresentadas à Faculdade de Economia da Universidade de Coimbra.

NUNES, João Arriscado; MATIAS, Marisa (2003), “Controvérsia científica e conflitos ambientais em Portugal: o caso da co-incineração de resíduos industriais perigosos”, Revista Crítica de Ciências Sociais, $65,129-150$.

NUNES, João Paulo Avelãs e ALVES, Helena (2004), “O sector extractivo em Portugal continental (1901-1953)”, em Manuel Heitor et al. (coords.), Momentos de Inovação e Engenharia em Portugal no Século XX. Vol. II, Publicações D. Quixote, 471-519.

OLIVEIRA, Jaime Manuel da Costa (2002), A Energia Nuclear em Portugal: Uma esquina da história, Santarém, O Mirante.

PEREIRA, Tiago Santos et al. (2008), A Ciência no Parlamento? Instituições, actores e risco. Coimbra, Centro de Estudos Sociais da Universidade de Coimbra.

PERRETI-WATEL, Patrick (2007), Sociologie du risque, Paris, Armand Colin.

ROMÃo, Maria Luísa et al. (2000), "Evolução da indústria extractiva por regiões no período de 1989 a 1998”, Boletim de Minas, 37(2), 91-123.

SANDMAN, Peter M. (1994), "Mass media and environmental risk: seven principles", Risk: Health, Safety and Environment, 5. Disponível em URL: <http://www.piercelaw.edu/risk/vol5/summer/ sandman.htm>, Acedido em: 23.10.2009.

SANTOS OLIVEIRA, J. M. et al. (1999), “Diagnóstico ambiental das principais áreas mineiras degradadas", Boletim de Minas, 39(2), 67-85.

SANTOS OLIVEIRA, J. M. et al., (2002), "Programa de investigação e controlo ambientais em áreas do país com minas abandonadas: Compilação de resultados”, Estudos, Notas e Trabalho, 41, 3-25.

SHWED, Uri; BEARMAN, Peter (2010), “The temporal structure of scientific consensus formation", American Sociological Review, 75(6), 817-840.

TAVEIRA, Amélia (2005). “Génese e instalação da Junta de Energia Nuclear (1950-1961)”. Disponível em URL: <http://.historia-energia.com/imagens/conteudos/OP1AT.pdf>, Acedido em: 14-03-2008.

TRASSARD, Cédric (2008), "O Ministério Público francês", em João Paulo Dias e Rodrigo Ghiringhelli de Azevedo (coords.), o Papel do Ministério Público: Estudo comparado dos países latinoamericanos, Coimbra, Almedina.

VEIGA, Carlos Jorge Mota (2006), Município de Nelas: Origem e evolução (dos princípios do século XIX à revolução de 1974), Nelas, Câmara Municipal de Nelas.

WYNNE, Brian (2006), "Public engagement as a means of restoring public trust in science: hitting the notes, but missing the music?', Community Genetics, 9(3), 211-220.

ZONABEND, Françoise (1993), The Nuclear Peninsula, Cambridge, Cambridge University Press. 


\section{NOTES}

1. Os resultados aqui apresentados reportam-se ao projecto de investigação "Risco, cidadania e o papel do Estado num mundo globalizado" (Ref.․ FCOMP-01-0124-FEDER-007550), financiado pela Fundação para a Ciência e a Tecnologia e realizado no Centro de Estudos Sociais da Universidade de Coimbra.

2. A história do nuclear em Portugal, permanecendo ainda em grande parte por contar, encontra válidos contributos em Oliveira, 2002. Relativamente à França, cf., entre outros, Hecht, 2004; Leridon, 2009.

3. O Comissariado para a Energia Atómica (CEA) é um estabelecimento público de carácter científico, técnico e industrial que tem por missão desenvolver aplicações da energia nuclear nos domínios científicos, industrial e da defesa nacional. O CEA foi criado em Outubro de 1945, pelo governo provisório do General Charles de Gaulle. De entre os diversos acontecimentos que marcaram a vida do CEA, salienta-se a fusão da filial CEA Indústrias com a FRAMATOME e a COGEMA para formar um novo grupo: a AREVA. A AREVA foi criada em Setembro de 2001, pela fusão da CEA Indústrias, da FRAMATOME e da COGEMA. O grupo detém, hoje, integralmente, a AREVA T\&D (Transmissão e Distribuição de Electricidade, adquirida à Alstom em 2004) e a AREVA NC (Nuclear Cycle), e 66\% da Areva NP (Nuclear Power, ex-FRAMATOME). A AREVA NC, COGEMA, até Março de 2006, quando todas as filiais da AREVA adoptaram uma nova identidade, pertence a $100 \%$ ao grupo AREVA e é especializada nas actividades ligadas ao ciclo do urânio enquanto combustível nuclear: exploração mineira, produção e enriquecimento do combustível, tratamento e reciclagem dos combustíveis usados, desmantelamento e requalificação das instalações.

4. O fechamento dos debates e das polémicas e a produção de consensos revelam também, nas suas temporalidades, os factores externos à ciência que condicionam e estruturam os campos científicos (Shwed e Bearman, 2010).

5. No caso português, vários estudos têm sido publicados que abordam o papel da ciência em controvérsias públicas. Para o caso da co-incineração, ver Jerónimo (2010), Matias (2009) e Nunes e Matias (2003); sobre o caso da barragem do Alqueva, ver Bento (2006). Para o estudo dos novos riscos em Portugal com estudos de caso sobre o urânio empobrecido, a BSE e a co-incineração, ver Gonçalves et al. (2007). Numa lógica distinta e num outro contexto teórico, cabe referir aqui o trabalho de Paulo Granjo como exemplo de uma análise do papel diferenciado dos saberes técnicos e científicos na gestão da produção e do quotidiano num contexto fabril de alta perigosidade em Sines (Granjo, 2004).

6. Para o caso francês, a autora fala de um Estado "administrador" ou "timoneiro" (stewardship politics).

7. Para uma análise excelente sobre as controvérsias em torno do armazenamento dos resíduos nucleares em França, e de como estes se tornaram problemas políticos, ver Y. Barthe (2006).

8. Para uma discussão de como em casos controversos as entidades oficiais mobilizam a ciência e a análise do risco para diminuir a incerteza, acabando numa primeira etapa por aumentar essa mesma incerteza, mas induzindo, no médio e longo prazo, novos processos de aquisição de conhecimentos, ver O. Borraz $(2011,2008)$. O autor propõe uma análise mais abrangente do papel da incerteza na governação do risco.

9. Os jazigos de urânio mais importantes encontram-se localizados na região central do País (Beiras), dispostos na parte ocidental do Maciço Hespérico, abrangendo a Cordilheira Central (Serra da Estrela, Lousã, S. Pedro de Açor, Gardunha) e estendendo-se para poente até às Serras do Buçaco, Caramulo e Montemuro. Na região centro, o urânio foi explorado em diversas minas 
das quais se salientam as minas da Urgeiriça, Bica, Castelejo, Cunha Baixa, Quinta do Bispo e Pinhal de Soto (Romão et al., 2000: 103).

10. Criada pelo Decreto-Lei n. ${ }^{3} 39580$, de 29 de Março.

11. A avaliação dos impactos ambientais da actividade mineira em Portugal encontra antecedentes que remontam a meados da década de 90. Para a análise dos antecedentes ao Programa de Reabilitação Ambiental de Áreas Mineiras Abandonadas, cf. Santos Oliveira et al., 1999, 2002; Costa, 2000; Romão et al., 2000; Batista, 2004, 2005; Mendes e Araújo, 2010.

12. As DDAS têm por missão a observação e aplicação das políticas de integração, de inserção, de solidariedade e de desenvolvimento social, e a prevenção em matéria de saúde pública, protecção sanitária do ambiente, controlo das normas de higiene, tutela e controlo dos estabelecimentos sanitários, médico-sociais e sociais.

13. As DRIRE são um serviço desconcentrado do Ministério da Economia, Indústria e Emprego para as competências relevantes dos ministérios da Ecologia, Desenvolvimento e Ordenamento Sustentáveis. As missões e acções da DRIRE são múltiplas e exercem-se nos seguintes domínios: 1) apoio às empresas; 2) metrologia; 3) ambiente; 4) energia; 5) veículos; 6) aparelhos pressurizados; 7) subterrâneos, minas, pedreiras e águas minerais, desenvolvimento sustentável.

14. Para uma análise detalhada do processo contra a COGEMA, vide Mendes et al., 2010.

15. A CRII-RAD é uma associação sem fins lucrativos dotada de um laboratório de análise que detém um certificado de qualificação técnica pelo Ministério da Saúde francês. A especificidade da CRIIRAD advém da sua independência relativamente ao Estado e aos agentes económicos, só possível graças às cotizações dos membros aderentes, das dádivas e dos estudos, análises e peritagens encomendados. A criação da CRII-RAD, em 1986, coincide com a tragédia de Tchernobyl. De facto, foi a partir da escassez de informação e de tomadas de posições firmes relativamente às consequências deste acidente para o ambiente e para o ser humano que a CRIIRAD se constituiu. A CRII-RAD tem, deste modo, por vocação: 1) controlar e informar as populações sobre as poluições radioactivas e os riscos associados ao nuclear; 2) atentar à permanência, aplicação e melhoria das regras de controlo e de protecções radioactivas existentes; 3) e assegurar a aplicação das medidas de protecção sanitária avaliadas como necessárias.

16. Para uma análise dos poderes do Ministério Público em França, cf. Trassard, 2008.

17. A ANPER-TOS, tal como a FNE, associa-se à SRL numa fase posterior do processo. Segundo Antoine Gatet, da SRL, a integração da ANPER-TOS com parte civil do processo deveu-se à intenção de conferir uma dimensão nacional à questão no domínio da água: "Nós iniciámos o processo em 1999 e, progressivamente, apercebemo-nos de que, para que o dossiê tivesse uma importância nacional, tinha de haver o concurso de associações nacionais. A FNE juntou-se a nós como parte civil e, no domínio das águas, fomos ter com a ANPER-TOS que nos disse que sim desde que não houvesse custos implicados" (entrevista a Antoine Gatet, SRL, 19.01.2009).

18. Note-se que, em Outubro de 2003, a SRL havia solicitado à Direcção Regional da Indústria, Investigação e Ambiente da Região Limousin que lhe comunicasse os controlos efectuados à COGEMA na última década. Na ausência de reposta, em Dezembro de 2003 a SRL recorre à Commission d'Accès aux Documents Administratifs (Comissão de Acesso aos Documentos Administrativos). A Direcção Regional da Indústria, Investigação e Ambiente indica que, em virtude do volume de informação, necessitará de mais tempo. Uma vez mais, a SRL escreve à Direcção Regional da Indústria, Investigação e Ambiente desta feita para comunicar a intenção de recorrer ao Tribunal Administrativo. Os documentos são, então, enviados e a SRL verifica que a Direcção Regional da Indústria, Investigação e Ambiente sempre se sustentou nas análises da COGEMA para validar as suas informações, não tendo ela própria realizado qualquer exame ao estado das águas, à natureza dos produtos armazenados ou aos níveis de perigosidade. 
19. Página oficial da SRL (http://www.sources-rivieres.org/): histórico do dossiê contra a COGEMA (1999-2006) (http://www.sources-rivieres.org/IMG/pdf/ historiquedossiercogemaSRL-2.pdf, acedido em Março de 2009).

20. As CLIS são estruturas de informação e concertação obrigatoriamente criadas, em França, ao abrigo da legislação sobre instalações classificadas para a protecção do ambiente. Têm por principal missão a informação ao público relativamente às questões da segurança, saúde do acompanhamento das actividades com potencial efeito na saúde e no ambiente. No domínio do nuclear existem, em França, cerca de 45 CLIS. As CLIS são compostas por representantes locais e regionais, membros do Parlamento eleitos pelo departamento, representantes das associações ambientais, dos interesses económicos, dos sindicatos, profissionais da saúde e personalidades qualificadas. Reúne-se pelo menos duas vezes por ano e organiza uma informação regular sobre as informações que lhe são comunicadas.

21. Um GEP é um espaço de diálogo técnico que congrega peritos científicos de diversas disciplinas por iniciativa das autoridades públicas (Ministérios do Ambiente e da Saúde). É um espaço de mediação que intervém em questões complexas e conflituais. A sua missão consiste não em realizar directamente peritagens mas em avaliar as peritagens realizadas pelos envolvidos para emitir pareceres e recomendações. Contribui ainda para a informação das comissões locais de informação e vigilância, as CLIS, ou outras estruturas locais de concertação. No domínio do nuclear existem apenas duas estruturas deste tipo em França, ambas criadas na sequência de polémicas no centro das quais se encontra a COGEMA: a primeira foi criada em 1997, no Norte de França, na Hague, onde se encontra uma instalação nuclear de tratamento de resíduos nucleares, na sequência de um estudo epidemiológico que apontava para a incidência aumentada de leucemias; a segunda foi criada em 2006, para monitorizar as actividades de requalificação e gestão dos antigos sítios mineiros da região Limousin. O Grupo de Peritagem Pluralista das Minas do Limousin (Groupe d'Expertise Pluraliste Mines du Limousin, GEP) parte do passivo ambiental legado pela exploração mineira ao território e da necessidade de proceder a "um intenso trabalho técnico e administrativo de modo a assegurar a requalificação desses sítios". Foi neste contexto, aliás, que o prefeito da Haute-Vienne, através de um regulamento da prefeitura de Janeiro de 2004, solicitara à COGEMA um balanço da situação regulamentar e das condições de reabilitação dos antigos sítios mineiros. Entregue o balanço em Dezembro do mesmo ano, o GEP ficou responsável por o submeter a uma peritagem com o objectivo de "esclarecer os poderes públicos sobre a gestão actual dos sítios mineiros do departamento e os diferentes impactos sanitários e ambientais desta decorrentes". A missão do GEP consiste, deste modo, em: acompanhar regularmente o desenrolar da peritagem e de participar à sua pilotagem; ter um olhar crítico sobre os documentos técnicos fornecidos pela COGEMA de modo a esclarecer a administração e a entidade exploradora relativamente às opções de gestão e de vigilância das instalações; formular recomendações no sentido de reduzir os impactos dos sítios mineiros sobre as populações e o ambiente; propor perspectivas de gestão dos sítios a longo prazo; e participar na informação aos actores locais e ao público (Carta de Missão do GEP, 9.11.2005).

22. Os resultados e recomendações do estudo foram divulgados em dois relatórios científicos (INSA, 2005; 2007, http://www.onsa.pt/conteu/est_proj_minurar.html, acedido em: 03.04.2009).

23. Para a análise de alguns dos contornos que vem assumindo a relação entre ciência e poder em Portugal, cf., entre outros, Gonçalves, 2007a e 2007b; Gonçalves et al., 2007; Nunes, 2007; Pereira et al., 2008; Mendes e Araújo, 2010.

24. A comunicação social desempenha uma importante função amplificadora, não do risco para a saúde pública em si (Sandman, 1994), mas da imagem dos trabalhadores contaminados, do drama, o fundamente ético e moral na base do qual os trabalhadores reclamam a responsabilização pelo Estado.

25. As reivindicações dos trabalhadores haviam chegado à Assembleia da República uma primeira vez em Março de 2008, por iniciativa de três partidos: 1) os projectos de lei n.ำ 412/X e n.․ 464/X, 
apresentados pelo BE, visavam alterar o Decreto-Lei n.․ 28/2005, alargando o regime aí previsto a todos os ex-trabalhadores da ENU, independentemente da data da cessação do vínculo profissional e visava a não-prescrição do direito à indemnização emergente de doenças profissionais por parte de todos os ex-trabalhadores da ENU abrangidos pelo DL n.. 28/2005; 2) o projecto de lei $\mathrm{n} .{ }^{\circ} 443 / \mathrm{X}$, apresentado pelo $\mathrm{PCP}$, visava alterar o regime jurídico de acesso às pensões de invalidez e velhice pelos trabalhadores da ENU; e 3) o projecto de lei n.. 468/X, apresentado pelo PSD, visava alterar o regime jurídico de acesso às pensões de invalidez e velhice pelos trabalhadores da ENU. Nenhum dos projectos de lei será, por oposição do partido maioritário (PS), aprovado. Mantendo-se os protagonistas, as reivindicações dos trabalhadores regressam à Assembleia da República numa conjuntura mais favorável, na medida em que o principal opositor, o PS, já não detém a maioria absoluta, e vêem aprovada a Lei n.․10/2010, de 14 de Junho, que altera o Decreto-lei n.. 28/2005 e alarga o seu âmbito aos trabalhadores que tenham exercido funções ou actividades de apoio nas áreas mineiras e anexos mineiros ou em obras ou imóveis afectos à exploração da Empresa Nacional de Urânio SA à data da sua dissolução, ou, no caso de cessação de contrato anterior à dissolução, que tenham aí trabalhado por período não inferior a quatro anos, bem como estabelece a obrigatoriedade de acompanhamento médico a estes trabalhadores. De fora fica a questão das indemnizações das viúvas dos trabalhadores, um grupo importante na mediatização do conflito.

\section{ABSTRACTS}

Procura-se neste artigo salientar as diferentes configurações que, em França e em Portugal, assume a relação entre o Estado, o território e a população, quando mediadas pela "redescoberta" da nuclearidade do urânio, tomando como pontos de entrada, no caso francês, o processo judicial que opôs uma associação ambientalista da região do Limousin à COGEMA e, no caso português, nos inesperados protestos que emergiram na sequência da requalificação ambiental da área mineira da Urgeiriça. Argumenta-se que tanto em França como em Portugal o processo de normalização decorreu sem mudanças significativas ou reconfiguração dos direitos de cidadania. Os territórios do urânio foram abordados como desafios técnicos: em França, no contexto do seu excepcionalismo nuclear, com a implementação de controlos administrativos mais rigorosos e um regime de regulação mais bem codificado; em Portugal, com a presença de vítimas e sem mudanças relevantes a nível da regulação. Em ambos os casos também é possível analisar o papel da ciência nas controvérsias públicas e na esfera pública. No caso francês, para legitimar as políticas públicas e a acção da empresa do nuclear, situando o debate numa dimensão especializada e fora dos recursos organizacionais e financeiros das associações ambientalistas.

Em Portugal, como conhecimento mobilizável para sustentar reivindicações e fornecer os factos necessários à produção de narrativas em torno de corpos contaminados, por analogia com o território.

In this paper we highlight the different configurations that the relationship between the State, the territory and the population assume in France and Portugal, when mediated by the rediscovery of uranium's nuclearity. Our exemples pertain to the judicial case put forward by a local environmental association in the region of Limousin against COGEMA and, in the case of Portugal, of the unexpected protests that emerged following the environmental requalification of Urgeiriça's uranium area. We conclude that both in France and Portugal the normalization 
process occurred without significant changes or reconfigurations in citizenship rights. The uranium territories were approached as technical challenges: in France, in the context of its nuclear exceptionalism, without victims and with the implementation of more rigourous administrative controls and a better codified regulation regime. In Portugal, with the presence of victims and without relevant changes in the regulation process.

In both cases it is also possible to analyse science's role in public controversies and in the public sphere. In the French case, to legitimize public policies and the actions of the company of nuclear energy, situating the debate in a specialized realm outside of the organizational and financial resources of environmental associations. In Portugal, as knowledge that can be mobilized to sustain grievances and to further the necessary facts to produce narratives, in an analogy with the territory, of contaminated bodies.

Cet article vise à mettre en lumière les diferentes configurations qui, en France et au Portugal, assument les relations entre l'État, le territoire et les populations suite à la «redécouverte» de la nucléarité de l'uranium. Prenant appui, pour le cas français, sur le procès judiciaire qui a opposé une association environnementale de la région Limousin à la COGEMA et, pour le cas portugais, les inattendues protestations locales suites à la récupération environnementale de la zone minière de l'Urgeiriça, nous argumentons que, en France comme au Portugal, le processus de normalisation a occuru sans que ne se vérifient de significatives changements ou reconfigurations des droits de citoyenneté, étant les territoires de l'uranium abordé et traité comme des défis techniques. En France, dans un context d'exceptionnalisme du nucléaire, le processus se réalise sans victimes, mais avec une implémentation plus rigoureuse des contrôles administratifs; au Portugal, le processus se réalise contant sur la présence de victimes mais sans conduire a des changements significatifs du régime de régulation. En les deux cas, il est également possible d'analyser le rôle de la science sur les controverses publiques et sur la sphère publique.

Dans le cas français, pour légitimer les politiques publiques et l'action de l'entreprise du nucléaire, en situant le débats dans une dimension spécialisée et en-dehors des recours organisationnelles et financiers des association environnementale. Au Portugal, comme connaissance mobilisable pour supporter des revendications et fournir le faits nécessaires à la production de narratives autor des cops contaminés par analogie au territoire.

\section{INDEX}

Mots-clés: état, citoyenneté, nucléarité, analyse comparative, France, Portugal, protestations sociales

Keywords: state, citizenship, nuclearity, comparative analysis, movements and social protest Palavras-chave: estado, cidadania, nuclearidade, análise comparativa, França, movimentos e protesto social

\section{AUTHORS}

\section{JOSÉ MANUEL MENDES}

Professor da Faculdade de Economia da Universidade de Coimbra e Investigador do Centro de Estudos Sociais da Universidade de Coimbra, jomendes@ces.uc.pt

PEDRO ARAÚJO

Investigador do Centro de Estudos Sociais da Universidade de Coimbra, paraujo@ces.uc.pt 